\title{
Tell me how you feel and I will tell you who you are: First validation of the affect integration inventory
}

psykologisk.no/sp/2017/01/e2/

\section{In this article, we present the first empirical validation of the Affect Integration Inventory (AII), a measure that assesses affect integration through a time-efficient self-report format, write Ole André Solbakken and colleagues.}

BY: Ole André Solbakken, Mari Rauk, Anders Solem, William Lødrup and Jon T. Monsen

The capacity to deal effectively with one's emotions, follow their guidance, harness their energy, and channel their power into healthy motivation, communication, and behavior is a hallmark of the well-adjusted individual. Conversely, failures in some or all of these areas lead to various forms of breakdown in psychological functioning (Monsen \& Monsen, 1999; Solbakken, Hansen, \& Monsen, 2011a). With a common term, these processes may be referred to as affect integration (Krystal, 1974; Monsen, Eilertsen, Melgård, \& Ødegård, 1996; Stolorow, Brandchaft, \& Atwood, 1995;

Solbakken, Hansen, Havik, \& Monsen, 2011b; Tomkins, 1963).

Affect integration is theoretically defined as the functional and fluent integration of affect in cognition, motivation, and behavior. It specifically refers to the availability of affect to propel, guide, and inform the individual in his interactions with his surroundings (Monsen \& Monsen, 1999; Solbakken, 2011; Stolorow et al., 1995). Consequently, adequate affect integration is characterized by the capacity for utilizing one's affects for adaptive purposes at both deliberate reflective and implicit unreflective levels (Solbakken et al., 2011a). This capacity is thought to protect against the development of psychopathology by ensuring appropriate and affectively informed responses to the ever-changing conditions surrounding the individual in the world (Monsen et al., 1996; Monsen \& Monsen, 1999; Stolorow et al., 1995; Solbakken, 2011; Tomkins 2008a, 2008b).

So defined, the construct domain covered by the affect integration concept reflects: 1 ) the capacity for accessing and utilizing the adaptive properties of affects for personal adjustment-what might be termed emotion utilization (Izard, Stark, Trentacosta, \& Schultz, 2008; Solbakken et al., 2011a)—and 2) the more general capability of tolerating and regulating affective activation-commonly denoted as emotion regulation (Gross, 2007; Solbakken et al., 2012).

Numerous related and partially overlapping concepts exist in the literature, such as 
alexithymia (Bagby, Parker, \& Taylor, 1994; Lesser, 1981), levels of emotional awareness (Lane, Quinlan, Schwartz, Walker, \& Zeitlin, 1990), mentalized affectivity (Fonagy, Gergely, Jurist, \& Target, 2002; Jurist, 2005), emotion regulation (Gross, 2007), and emotional intelligence (Salovey \& Mayer, 1990). However, common to all of these is that to a very limited degree they place emphasis on the importance of differentiating between various emotions or affect states in assessment. Thus, what first and foremost sets the present conceptualization of affect integration apart from these theoretical counterparts is its operationalization into a scoring system comprising a large number of discrete affect categories (Choi-Kain \& Gunderson, 2008; Solbakken et al., 2012). We believe that such differentiation is essential if we are to understand the differential signal and motivational impacts of discrete affect states and if we are to fully comprehend how the capacity to deal effectively with emotions influences psychological functioning and mental health (Tomkins, 2008a, 2008b; Izard, 2007; 2009; Damasio, 1999; 2004; LeDoux, 1996; Solbakken et al., 2011a; Solbakken et al., 2012).

Affect integration has been commonly operationalized through the Affect Consciousness construct and assessed by use of the semi-structured Affect Consciousness Interview (Monsen, Monsen, Hansen, \& Solbakken, 2008). Numerous studies have indicated the usefulness of this conceptualization at both clinical and theoretical levels (e.g., Monsen, Ødegård, \& Melgård, 1989; Monsen et al., 1996; Monsen \& Monsen, 1999; McCullough Vaillant, 1997; Falkenström, Solbakken, Möller, Lech, Sandell, \& Holmqvist, 2014; Gude, Monsen, \& Hoffart, 2001; Johansen, Normann-Eide, Normann-Eide, \& Wilberg, 2013; Normann-Eide, Johansen, NormannEide, Egeland, \& Wilberg, 2013; Waller \& Scheidt, 2004; Holmqvist, 2008; Lech, Andersson, \& Holmqvist, 2008; Choi-Kain \& Gunderson, 2008; Solbakken et al., 2011b; Solbakken et al., 2012; Taarvig, Solbakken, Grova, \& Monsen, 2014).

The Affect Consciousness Interview ( $\mathrm{ACl}$ ) operationalizes affect integration as the individual's capacity to consciously perceive, tolerate, reflect upon, and express the experiences of basic affective activation. Observer-based assessments are made of the respondents' capacity for awareness, tolerance, emotional (i.e., nonverbal) expression, and conceptual (i.e., verbal) expression of a number of discrete affect categories (Monsen, Melgård, \& Ødegård, 1986; Monsen, et al., 1996; Monsen et al., 2008). Most commonly, studies have used a version of the interview with nine affect categories represented, including 1. Interest/Excitement, 2. Enjoyment/Joy, 3.

Fear/Panic, 4. Anger/Rage, 5. Shame/Humiliation, 6. Sadness/Despair, 7. Envy/Jealousy, 8. Guilt/Remorse, and 9. Tenderness/Care. These affect states are thought of as basic, biologically founded response categories that can vary in intensity and duration. Through experience and development, the way they are experienced and expressed becomes organized in highly individualized patterns or scripts (Izard \& Ackerman, 2000; Panksepp, 1998; Tomkins, 1995, 2008a, 2008b; Solbakken et al., 2011a). 
The main problem with the $\mathrm{ACl}$ is that it is time-consuming (commonly two hours of interviewing and usually twice that for scoring). Also, a fair amount of training is required for those who want to master it (usually 30 to 40 hours including lectures and supervision on ratings). Thus, the potential proliferation of the method and construct is reduced due to capacity issues in terms of training and time issues in the clinical and research setting.

It has therefore been an important priority to develop a method for assessing affect integration that is more easily accessible and less arduous to use than the $\mathrm{ACl}$. Consequently, the Affect Integration Inventory (AII) was developed (Solbakken \& Monsen, 2013). The All is a medium-length (112 items) self-rated assessment instrument that endeavors to measure capacities for experience and expression of the nine affect states most commonly assessed with the $\mathrm{ACl}$ in previous studies.

The present article constitutes the first empirical validation of this new measure. Hopefully it will lay the grounds for many new studies and make the empirical examination of affect integration more accessible for interested researchers across the world.

\section{Aims of the study}

The present study tests the usefulness of a new assessment instrument-the Affect Integration Inventory (AII) - in measuring capacity for affect integration. We examine the reliability and validity of the All in a sample of 157 non-clinical respondents. The study includes estimates of internal consistency reliability, examination of internal structure by factor analyses, and investigation of convergent and discriminant validity in terms of its relationships to a number of theoretically central external criteria. We also test the usefulness of systematically differentiating among discrete affect states by examining the presence of theoretically expectable and empirically specific patterns of relationships between the capacity for integration of separate affects and specific types of interpersonal problems. Thus, the present study constitutes a relatively comprehensive first validation of the All.

\section{Research hypotheses - internal domain study}

In examining the structural properties of scores from the All we first investigate internal consistency reliability across the various All scores. We then examine whether scores from the All have a theoretically feasible factorial structure. We do this by two separate sets of analyses. First, we explore the factor structure of experience and expression scores across all affects to examine if differentiation of discrete affects in the All is empirically supported. Second, we test whether discrete affect scores are organized according to the underlying dimensions that are currently held as constituting the most representative account of similarities and differences in emotional experience.

Fontaine, Scherer, Roesch, and Ellsworth (2007) have convincingly shown that the dimensions of valence-pleasantness, potency-control, and activation-arousal are the three most important for adequately representing commonalities and differences across various emotions and affective states. If scores from the All were organized 
accordingly, they would constitute further evidence for the validity of affect scores derived from the instrument.

\section{Research hypotheses - associations with external factors}

To test the convergent and discriminant validity of scores from the All, we examine correlations with a number of relevant external criteria. As a test of criterion-related convergent and discriminant validity, we explore the associations between All scores and measures of the partly overlapping concepts of emotion regulation and alexithymia. We then explore associations with a number of central external criteria expected to be associated with All scores as operationalized by well-established measures of psychological symptoms, social role dysfunction, and relational dysfunction / interpersonal problems.

Based on theoretical inference and previous studies, we can generate specific hypotheses about the nature of these relationships. These hypotheses can then be put to the test in order to inform us about the convergent and discriminant validity of scores from the All.

Affect integration and emotion regulation - We expect robust but differentiated associations between All scores and scores of emotion regulation. More specifically, we postulate that All scores in general will be less strongly correlated with the emotionregulating process of reappraisal than with the process of expression suppression (Gross, 2007). This tendency stems from the fact that reappraisal does have some elements in its operationalization that indicate a subtle but unmistakable tendency for willfully suppressing the activation of emotion by rethinking and reinterpreting the situation that elicited it. Because this capacity is associated with being able to handle emotion effectively, we do expect a positive association with affect integration. However, this association is probably weak to moderate since one hallmark of good affect integration is the fundamental acceptance of emotional activation and capacity for reflection upon its meaning rather than suppressing it through effortful control.

In contrast, we expect strong negative associations between affect integration and expression suppression since the content domain of this variable significantly overlaps with limitations in the capacity for expression as operationalized in the All. It is also indicative of a general reluctance to accept and acknowledge the impact of emotion upon the self, which is central to the operationalization of capacity for experiencing affect in the All. On the subscale level, we expect affect experiencing to be more strongly related to reappraisal than affect expression. Meanwhile, the converse is expected for the emotion-regulating strategy of expression suppression (i.e., affect expression is expected to be more strongly related to expression suppression than affect experiencing).

Affect integration and alexithymia - We expect negative and generally strong associations between All scores on all levels and alexithymia. Conceptually, these two constructs overlap substantially in terms of their content domain. On the subscale 
level, we expect a differentiated pattern of correlations between All scores and the three alexithymia subscales: difficulty identifying feelings (DIF); difficulty describing feelings (DDF); and externally-oriented thinking (EOT). The content domain of EOT has little direct conceptual overlap with affect integration as operationalized in the All. We therefore expect only weak or moderate associations between this subscale and All scores. (Some association is to be expected since this variable has been shown to be related to the other facets of alexithymia.) For DIF, we expect strong negative correlations with All scores on all levels. Since DIF operationalizes difficulties in awareness of emotion, we expect stronger associations between the All subscale of affect experiencing and DIF than between the affect expression subscale and DIF. Conversely, we expect DDF to be more strongly related to affect expression than to affect experiencing, since DDF primarily taps into the capacity for verbal expressions of emotion.

\section{Affect integration and psychological distress, psychiatric symptoms, relational, and social role (i.e., work-related) dysfunction - We expect strong negative} associations between All scores on all levels and overall levels of psychological distress (mean score on the OQ-45.2). On the subscale level, we expect affect experiencing to be more strongly related to the OQ-45.2 scales than affect expression. This is because an adaptive capacity for experiencing affects is, theoretically, a prerequisite for healthy psychological functioning, while capacity for expressing affect, even though also expected to be substantially associated with the OQ-45.2 subscales, is presumably somewhat less essential as long as the capacity for affect experiencing is adequate. Finally, we hypothesize that social role or work-related dysfunction is less strongly associated with affect integration than the other OQ-45.2scores, since problems with one's working arrangements may be influenced by a number of factors beyond those associated with one's coping with emotional reactions (especially in a normal sample as the one studied here).

\section{Affect integration and interpersonal problems - We expect strong negative} associations between All scores on all levels and interpersonal problems in general. In addition, as a further test of convergent and discriminant validity, we also postulate systematic variation in the patterns of relationships between the integration of discrete affects on the All and specific types of interpersonal problems (Solbakken et al., 2011b). Accordingly, based on the theoretically-derived motivational properties of different affects, we can make precise hypotheses about which interpersonal problem types are strongly linked to a low capacity for any given affect and which interpersonal problem types are not. Since the eight subscales of the IIP-64 are organized in a circular order constituting an interpersonal circumplex (Horowitz, Alden, Wiggins, \& Pincus, 2000), this measure is particularly well suited for testing hypotheses about the convergent and discriminant validity of scores from the All. The circular order of scales in the IIP-64 allows us to predict specific associations between discrete affect scores and interpersonal problem types by way of distinct sinusoidal patterns of associations, with the eight IIP octant scales peaking in separate and theoretically expected octants 
(Solbakken et al., 2012). Accordingly, we expect the following:

1. Problems with tenderness/care (typically interfering with the capacity for closeness, bonding, and attachment) are expected to have a correlation pattern peaking in the cold-detached (DE) octant, with gradually lower correlations having a low point in the self-sacrificing (LM) octant.

2. Problems with anger/rage (typically interfering with self-assertion and agency) are expected to have a correlation pattern peaking in the non-assertive $(\mathrm{HI})$ octant, with gradually lower correlations having a low point in the dominant (PA) octant.

3. Problems with jealousy (typically interfering with trust and tolerance of interdependence on the other) are expected to have a correlation pattern peaking in the vindictive (BC) octant, with gradually lower correlations having a low point in the overly accommodating (JK) octant.

4. Problems with interest/excitement, enjoyment/joy, shame/humiliation, and fear/panic (all of which typically interfere with closeness/bonding as well as assertive behavior and combinations of the two) are expected to have correlation patterns peaking in the socially avoidant (FG) octant, with gradually lower correlations having a low point in the intrusive (NO) octant.

Figure 1 illustrates graphically the four distinct sinusoidal patterns of correlations we expect between the various affects in hypotheses 1-4 above. It also shows the different types of interpersonal problems operationalized in the IIP-64. 


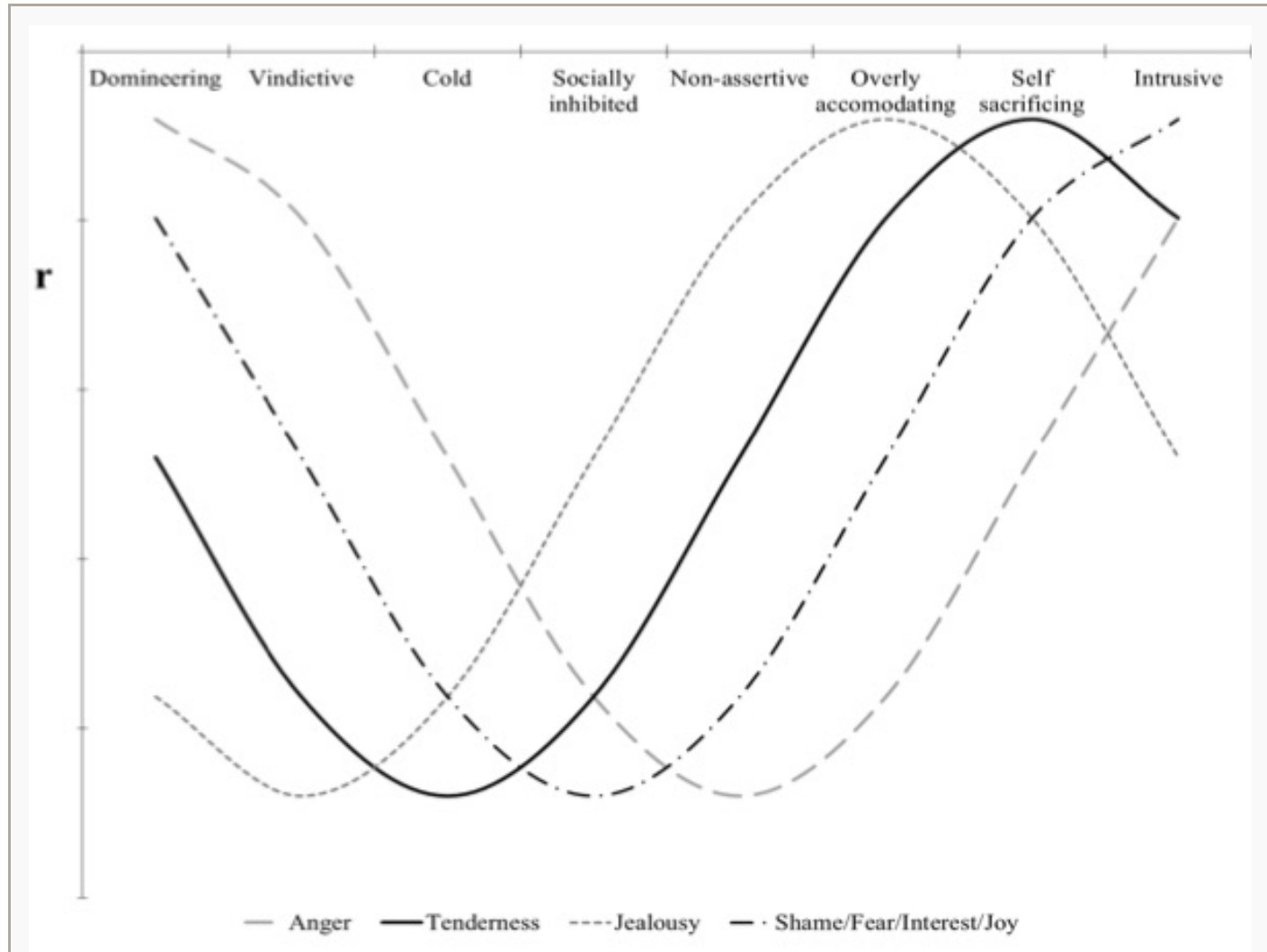

FIGURE 1: Predicted patterns of correlations between discrete affect scores from the All and IIP-64 subscales.

For the remaining two affects (sadness/despair and guilt/remorse), no specific hypotheses were generated. This is because theoretically speaking, problems with both sadness/despair and guilt/remorse are not clearly indicative of any specific interpersonal problem type. Rather, poor integration of both affects may potentially be strongly associated with a variety of interpersonal problems. We do, however, expect problems with both affects to be more strongly associated with problems on the left side of the interpersonal circumplex, since both are presumably central to establishing and maintaining close attachments to others.

\section{Method}

\section{Participants and procedures}

A questionnaire including a number of psychological measures was anonymously completed by 157 respondents. Forms were completed by use of paper and pencil either at lectures or in the respondents' own homes. Forms were either collected at the end of the lectures or sent in by mail in a pre-stamped envelope. Completing the form commonly took about 45 minutes. In total, there were three cases that hadn't completed the alexithymia measure; all other measures were completed for all 157 participants. The three cases with missing data were dropped from the analyses of alexithymia. Females constituted $70.7 \%$ of the sample and males $28.8 \%$. Mean age was 27 years (range: 16-90). Respondents had an average of 14.4 years of education 
including primary school, secondary school, high school, and college/university level. The majority of respondents were students.

\section{Assessment Instruments}

The Affect Integration Inventory (AII) - The All is a freshly developed self-report instrument for efficient and effective assessment of affect integration. It was developed on the basis of a large number of relevant statements about awareness, tolerance, and expressions of discrete emotions, which were selected and categorized from a total of 403 clinical affect consciousness interviews. In total, 720 statements were extracted corresponding to 20 statements for each of the integrating aspects across affects in the $\mathrm{ACl}$ respectively. These statements were then systematized and summarized through conceptual analysis before a condensed list was derived that represented common themes from the initial list. Ultimately, a set of 112 items was derived and formulated. These items represented a summary of the most typical ways of experiencing and expressing the nine affects as described by the respondents in their interviews. The items, as they were then formulated, were thought to constitute the most relevant, precise, and recognizable representation of common descriptions associated with the integration of the various affects in the $\mathrm{ACl}$.

The first version of the instrument was then tested in a small sample of psychology students. Based on the responses in this sample, along with qualitative feedback on the quality of separate items in terms of their perceived face validity among respondents, a total of 13 items were reformulated or replaced due to significant variation in the way the original items were interpreted and responded to. The 13 new items were in turn tested in a new student sample and deemed acceptable. Thus, after this revision, the AAl could be articulated in its current version. All items in the final version were classified as easily understood by the test sample.

The All then is a 112-item instrument that assesses the integration of nine discrete affect states: 1. Interest/Excitement; 2. Enjoyment/Joy; 3. Fear/Panic; 4. Anger/Rage; 5. Shame/Humiliation; 6. Sadness/Despair; 7. Jealousy/Possessiveness; 8. Guilt/Remorse; and 9. Tenderness/Care. Across these affects or emotions, items are chosen to tap the capacity for adaptive experience and adaptive expression. In total, 82 items are indicators of capacity for experience, while 30 items are indicators of capacity for expression. The discrepancy in the number of items in the two domains was due to the greater variation in typical statements pertaining to experience as compared to statements about expression. Each item is rated on a 10-point Likert scale ranging from doesn't fit at all (0) to fits perfectly (9), mirroring the scale used for rating the ACI. Items are phrased to tap into how the respondent usually experiences or expresses each affect. High scores reflect higher levels of affect integration.

The All yields scores on three different levels:

1. Overall score across all items (global affect integration) 
2. Mean score on capacity for experience across affects (affect experience) and mean score on capacity for expression across affects (affect expression)

3. Mean score for the integration of each discrete affect (e.g., integration of tenderness/care, anger/rage, enjoyment/joy, etc.)

Example items for capacity for experience include: "When I am sad it is usually about important things in my life"; "I often don't notice that I am anxious before the feeling is very strong" (reverse coded); and "I feel guilty about far too many things" (reverse coded). Example items for capacity for expression include "It is ok for me to show others that I am angry"; "I usually pretend not to be jealous even if I feel it intensely" (reverse coded); and "I usually tell others about it when I feel happy."

The Emotion Regulation Questionnaire (ERQ - Gross \& John, 2003) - The ERQ is a 10-item, self-report measure of habitual expressive suppression (four items) and reappraisal (six items) in relation to emotions (Gross \& John, 2003). The ERQ uses a seven-point Likert scale ranging from 1 (strongly disagree) to 7 (strongly agree). Example questions include: "I control my emotions by changing the way I think about the situation I'm in" (reappraisal) and "I control my emotions by not expressing them" (expressive suppression). The ERQ has been shown to have good psychometric properties. Expressive suppression has been consistently linked to increased depression, anxiety, symptoms of stress, and poorer well-being, while reappraisal has been shown to correlate with greater positive emotion and less negative emotion, better interpersonal functioning, better social adjustment, and positive well-being (Gross \& John, 2003; Spaapen, Waters, Brummer, Stopa, \& Bucks, 2014). Cronbach's alpha in the study sample was .75 for reappraisal and .78 for expressive suppression.

The Toronto Alexithymia Scale 20 (TAS -20 - Bagby et al., 1994) - The TAS-20 is a widely studied self-report scale composed of 20 items (Bagby et al., 1994). Each item is rated on a five-point Likert scale ranging from 1 (strongly disagree) to 5 (strongly agree). Five items are reverse scored. There are three subscales scores and a total score derived from the instrument. The first subscale consists of seven items assessing the ability to identify feelings and to distinguish them from the somatic sensations that accompany emotional arousal (DIF). Example items include: "I am often confused about what emotion I am feeling" and "I have feelings that I can't quite identify." The second subscale consists of five items assessing the ability to describe feelings to other people (DDF). Example items include: "I am able to describe my feelings easily" and "It is difficult for me to reveal my innermost feelings, even to close friends." The third subscale consists of eight items assessing externally oriented thinking (EOT). Example items include: "I prefer to analyze problems rather than just describe them" and "Looking for hidden meanings in movies or plays distracts from their enjoyment." In the study sample, Cronbach's alpha for the total score of the TAS20 was .84, for DIF it was .84, for DDF it was .72, and for EOT it was .67.

The Outcome Questionnaire 45.2 (OQ-45.2 - Lambert, Morton J., Hatfield D., 
Harmon C., Hamilton S., et al, 2004) - The OQ-45 is a 45-item self-report instrument that measures psychological distress overall and in three separate subdomains. It is rated on a five-point Likert scale ranging from 0 (never) to 4 (almost always). Higher scores are indicative of greater levels of psychological distress. The OQ-45 is currently perhaps the most commonly used indicator of psychological distress, symptoms, and dysfunction in psychotherapy research. The sum of all items gives a total distress score (TD). There are three subscales: symptom distress (SD), which covers mainly depression, anxiety, and psychosomatic complaints (25 items); interpersonal relations (IR), which measures distress in both intimate and more peripheral relationships (11 items); and social role functioning (SR), which measures problems in everyday functioning in areas such as work, school, and home (9 items) (Lambert et al., 2004). Cronbach's alpha for the TD score was .95, for SD it was .93, for IR it was .79, and finally for SR it was .81.

The Inventory of Interpersonal Problems 64 (IIP-64 - Horowitz et al., 2000) Interpersonal problems were assessed with the 64-item IIP circumplex version (Horowitz et al., 2000). The IIP-64 consists of two types of items. The first 39 begin with the phrase: "It is hard for me to...." The remaining 25 represent "things that you do too much." Each item is rated on a five-point Likert scale ranging from not at all (0) to very much (4). The general factor of the IIP-64 has been consistently linked to symptom severity and negative affectivity (Tracey, Rounds, \& Gurtman, 1996). The second (Agency) and third (Communion) factors, yielding the IIP-64 circumplex structure, have shown good construct validity in terms of fit with a quasi-circumplex model and distinct convergent-discriminant correlation patterns with different forms of personality pathology. These findings support the view that the IIP-64 model effectively represents its presumed distinctions of interpersonal functioning (Monsen, Hagtvedt, Havik, \& Eilertsen, 2006).

The overall score of the IIP-64 is used as an indicator of general interpersonal problems (IIP-global). The IIP-64 also yields eight octant sum scores, indicating specific problems with being $P A=$ domineering/controlling, $B C=$ vindictive/selfcentered, $\mathrm{DE}=$ cold/distant, $\mathrm{FG}=$ socially inhibited, $\mathrm{HI}=$ non-assertive, $\mathrm{JK}=$ overly accommodating, $\mathrm{LM}$ = self-sacrificing, and NO = intrusive/needy. Cronbach's alpha for the IIP global in the study sample at intake was .94. For the eight octant scales, Cronbach's alpha ranged from .74 (intrusive/needy) to .97 (socially inhibited).

\section{Statistical analyses}

Descriptive statistics were computed. Internal consistency reliability was assessed by Cronbach's alpha for each of the scales derived from the All. Overall factor structure was assessed via principal axis factor analyses of experience and expression scores (mean score on experience and expression items for each affect respectively) across affects. Nine factors were requested based on the conceptual structure of the All (assessing nine discrete affects). The solution was then promax-rotated (oblique rotation) because factors derived from the All are expected to be substantially 
correlated. Due to the many parameters to be estimated (nine factors and 36 factor correlations), the factor analysis was done using a traditional factor analytic procedure rather than with structural equation modeling. That is because the latter approach demands a substantially larger sample size than was available in this case.

To further test whether discrete All affect scores were organized according to the underlying dimensions currently held to best account for similarities and differences among emotions, we conducted a principal component analysis of ipsative affect scores (the discrete affect score after subtraction of the grand mean across affects). This procedure removes common variance related to the general factor of the instrument and maximizes variation across scores. The dimensions extracted from the analysis were plotted against each other, creating an orthogonal space in which discrete affects may be represented by their respective coordinates. The placement of All scores was compared to the placement of emotions in Fontaine et al.'s (2007) definitive study. Associations with external criteria were assessed by Pearson's product-moment correlation analyses. Z-tests were conducted to assess the statistical significance of differences in correlation magnitudes to demonstrate convergent and discriminant validity.

\section{Results}

Descriptive statistics for the All, along with internal consistency reliability for the various subscales, are reported in Table 1. Cronbach's alpha values were generally very high, indicating good to excellent internal consistency for all derived scores. The exception was integration of shame/humiliation, for which internal consistency reliability was somewhat weaker than desired.

TABLE 1: Descriptive statistics and internal consistency reliability for All scores on all levels. 


\begin{tabular}{lllll}
\hline All-variable & $M$ & $S D$ & Range & $\alpha$ \\
\hline Global Al & 5.72 & 0.97 & $3.14-7.85$ & .96 \\
Experience & 5.73 & 0.97 & $3.06-8.16$ & .94 \\
Expression & 5.67 & 1.22 & $2.30-8-17$ & .91 \\
Specific affects & & & & \\
Interest & 6.11 & 1.19 & $2.67-9.00$ & .78 \\
Joy & 6.25 & 1.75 & $1.42-9.00$ & .93 \\
Tenderness & 6.23 & 1.55 & $2.31-9.00$ & .90 \\
Fear & 5.11 & 1.43 & $1.77-8.38$ & .83 \\
Anger & 5.66 & 1.20 & $2.69-8.62$ & .80 \\
Shame & 5.14 & 1.02 & $2.75-7.58$ & .57 \\
Sadness & 5.49 & 1.19 & $2.83-8.25$ & .76 \\
Jealousy & 5.67 & 1.66 & $1.23-8.69$ & .87 \\
Guilt & 5.82 & 1.31 & $1.67-8.42$ & .82 \\
\hline Note: Global Al = global affect integration; $M=$ mean; SD & & & \\
and $a=$ Cronbach's alpha & & &
\end{tabular}

\section{Internal structure}

The principal axis factor analyses of experience and expression scores across affects yielded nine factors that were readily interpretable. Factors corresponded to the nine affects assessed in the All. Both parallel analysis and scree plot inspection supported the feasibility of the nine-factor solution. Before rotation, the solution accounted for a total of $83.78 \%$ of the variation in the data. The pattern matrix after promax-rotation, along with factor correlations, is presented in Table 2 . As can be seen, a highly differentiated structure was identified wherein Integration of Anger, Guilt, Shame, Jealousy, and Tenderness loaded exclusively on expected variables. Integration of Joy and Sadness also loaded on expected variables, but both had one additional crossloading (expression of interest and expression of fear, respectively). Finally, the Integration of Fear and Interest factors loaded substantially on one of the expected variables each (experience of fear and experience of interest, respectively), while loadings on the corresponding expression variables were smaller than expected and did not reach the .35 mark. Factor correlations ranged from .68 to .19 , with a mean of .42 .

TABLE 2: Factor structure of experience and expression scores across affects along with obtained factor correlations. 


\begin{tabular}{|c|c|c|c|c|c|c|c|c|c|}
\hline & & & & & Factor & & & & \\
\hline Affect Integration Variable & F1 & F2 & F3 & $\mathrm{F} 4$ & F5 & F6 & F7 & F8 & F9 \\
\hline Experience of Joy & 0.83 & 0.01 & -0.02 & 0.03 & 0.26 & -0.02 & 0.04 & -0.05 & -0.01 \\
\hline Expression of Joy & 0.99 & -0.13 & 0.03 & 0.00 & -0.05 & -0.05 & -0.06 & 0.03 & 0.07 \\
\hline Experience of Sadness & -0.01 & 0.47 & 0.07 & 0.03 & 0.32 & -0.05 & 0.04 & 0.05 & -0.04 \\
\hline Expression of Sadness & -0.06 & 0.98 & 0.12 & 0.02 & -0.08 & -0.10 & 0.02 & -0.06 & -0.10 \\
\hline Experience of Guilt & -0.08 & -0.10 & 0.68 & 0.08 & 0.20 & -0.07 & 0.03 & 0.10 & -0.04 \\
\hline Expression of Guilt & 0.15 & 0.10 & 0.53 & -0.13 & 0.09 & 0.09 & -0.05 & -0.09 & 0.01 \\
\hline Experience of Anger & -0.06 & 0.10 & 0.15 & 0.52 & 0.31 & 0.12 & 0.04 & -0.15 & 0.03 \\
\hline Expression of Anger & 0.05 & -0.05 & -0.08 & 0.91 & -0.13 & -0.05 & -0.05 & 0.14 & 0.05 \\
\hline Experience of Fear & 0.04 & -0.03 & 0.17 & -0.05 & 0.75 & -0.02 & -0.02 & -0.03 & 0.05 \\
\hline Expression of Fear & -0.04 & 0.67 & -0.33 & -0.08 & 0.20 & 0.02 & 0.01 & 0.15 & 0.18 \\
\hline Experience of Jealousy & -0.12 & -0.25 & -0.01 & 0.00 & 0.01 & 0.82 & 0.14 & 0.03 & 0.06 \\
\hline Expression of Jealousy & 0.12 & 0.25 & 0.03 & -0.02 & -0.05 & 0.71 & -0.17 & 0.04 & -0.08 \\
\hline Experience of Interest & 0.12 & 0.05 & -0.01 & -0.04 & -0.01 & 0.03 & 0.92 & -0.03 & -0.01 \\
\hline Expression of Interest & 0.47 & 0.10 & -0.02 & 0.04 & -0.08 & 0.04 & 0.24 & 0.12 & -0.10 \\
\hline Experience of Shame & -0.02 & -0.06 & 0.29 & -0.10 & 0.31 & -0.01 & -0.01 & 0.45 & 0.08 \\
\hline Expression of Shame & 0.08 & 0.08 & 0.00 & 0.13 & -0.07 & 0.05 & -0.02 & 0.68 & -0.11 \\
\hline Experience of Tenderness & 0.05 & 0.04 & -0.01 & 0.06 & 0.12 & 0.01 & -0.02 & -0.09 & 0.84 \\
\hline \multirow[t]{9}{*}{ Expression of Tenderness } & 0.11 & 0.36 & 0.26 & 0.01 & -0.32 & 0.01 & 0.06 & 0.05 & 0.35 \\
\hline & \multicolumn{9}{|c|}{ Factor correlations } \\
\hline & & 0.68 & 0.50 & 0.27 & 0.36 & 0.33 & 0.59 & 0.57 & 0.66 \\
\hline & & & 0.42 & 0.28 & 0.32 & 0.36 & 0.45 & 0.57 & 0.66 \\
\hline & & & & 0.49 & 0.44 & 0.32 & 0.42 & 0.41 & 0.57 \\
\hline & & & & & 0.44 & 0.35 & 0.33 & 0.22 & 0.19 \\
\hline & & & & & & 0.41 & 0.53 & 0.42 & 0.38 \\
\hline & & & & & & & 0.31 & $\begin{array}{l}0.37 \\
0.35\end{array}$ & $\begin{array}{l}0.36 \\
0.44\end{array}$ \\
\hline & & & & & & & & & 0.48 \\
\hline
\end{tabular}

Note: Loadings of the pattern matrix from principal axis factor analysis with promax (oblique) rotation; Loadings above .35 are in bold.

In the principal component analysis of discrete affect scores, the expected threedimensional solution was deemed feasible both on the basis of parallel analysis and scree plot inspection. The solution accounted for $49.8 \%$ of the total variance. The first dimension accounted for $22.2 \%$ of the variance, the second for $14.5 \%$, and the third for 13.1\%. Respective factor loadings for each affect score are presented in Table 3. The rank orders of component scores for discrete affects on the three dimensions were generally in accordance with corresponding emotion terms and dimensions in Fontaine et al.'s data (2007) but with some deviations, particularly on the third dimension.

TABLE 3: The three dimensions from PCA of overall affect scores with eigenvalues and respective factor loadings. 
Component

\begin{tabular}{lccc} 
& 1 & 2 & 3 \\
\hline Eigenvalue & 2.00 & 1.30 & 1.18 \\
\hline Affect & & Loading & \\
\hline Joy & .76 & -.19 & -.21 \\
Anger & -.60 & -.01 & -.03 \\
Tenderness & .51 & .21 & -.10 \\
Interest & .51 & -.34 & .25 \\
Jealousy & -.53 & -.69 & .23 \\
Guilt & -.38 & .44 & -.39 \\
Shame & -.24 & .43 & .43 \\
Fear & -.03 & .14 & -.59 \\
Sadness & .22 & .51 & .57 \\
\hline
\end{tabular}

\section{Note: Principal component analysis of ipsative affect}

\section{scores}

Panels $a$ and $b$ of Figure 2 present the locations of various emotions and affective states when the three main dimensions (commonly termed 1) evaluation-pleasantness, 2) potency-control, and 3) activation-arousal respectively) are plotted against one another as demonstrated by Fontaine et al. (2007). Panels $c$ and d present the location of affects obtained from the principal component analysis of All scores. As can be seen, the locations of affects as measured by the All correspond well to the locations found for analogous emotion terms in Fontaine et al.'s large-scale multicultural and multilingual study. 


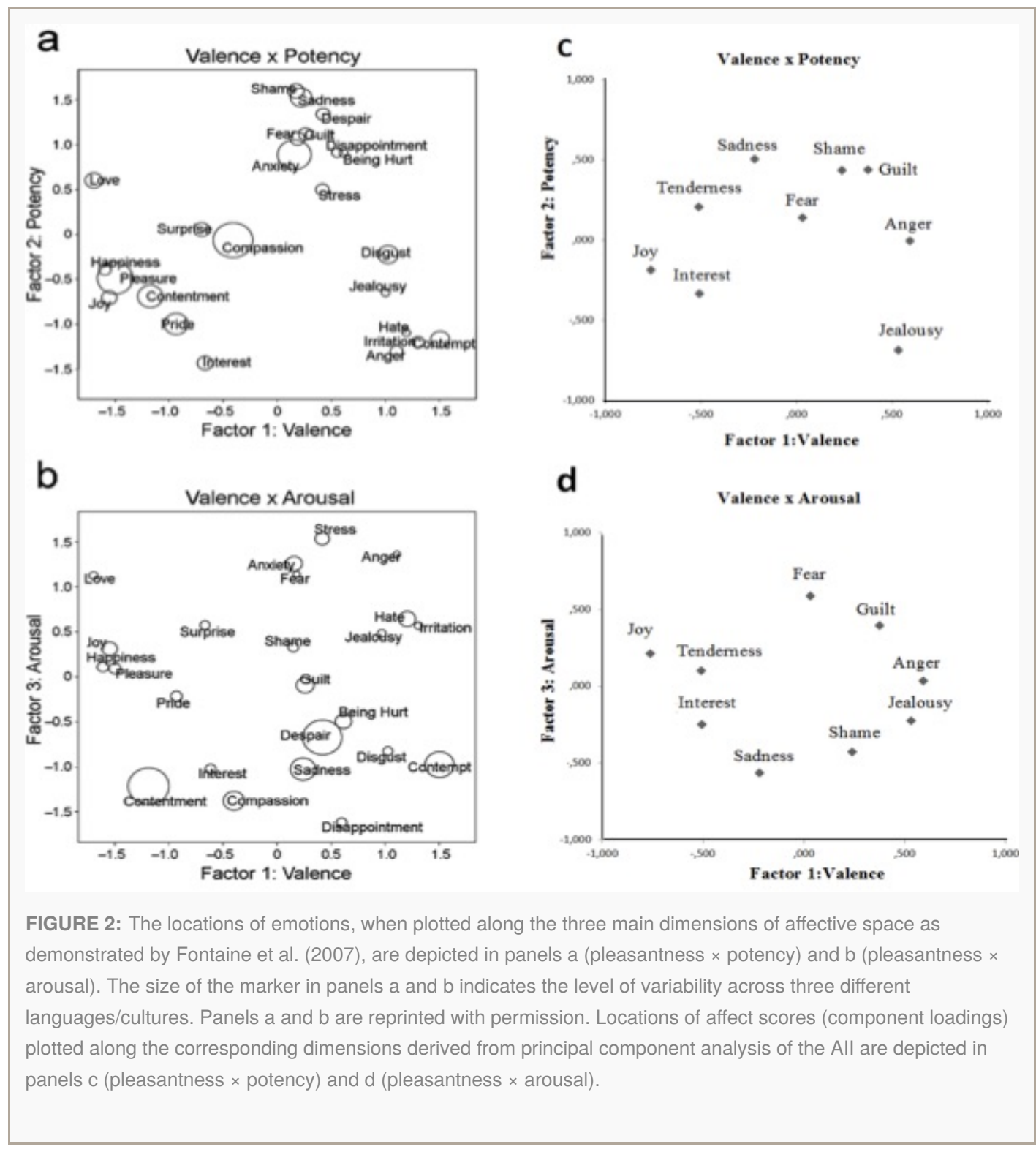

Specifically, when inspecting the valence $\times$ potency plot, we note that joy, interest, and tenderness are located in accordance with the expectations derived from Fontaine et al.'s data. So are shame, guilt, and fear. Sadness is placed close to expectation, but with slightly higher valence. Both anger and jealousy are, in accordance with expectations, placed as unpleasant, high-potency affects, but anger was associated with somewhat lower levels and jealousy with somewhat higher levels of potency than anticipated. Inspecting the valence $\times$ activation plot, a similar pattern appears. Again, joy, interest, and tenderness are located as expected. So are sadness, fear, anger, and jealousy. Shame and guilt are located as expected on the valence dimension. However, unlike the results obtained by Fontaine et al., shame and guilt were separated in our data as relatively low and high in arousal, respectively.

\section{Associations with external factors: relationships with emotion regulation, alexithymia, psychological distress, and global interpersonal problems}

Correlations between affect integration scores and measures of emotion regulation, alexithymia, psychological distress, and global interpersonal problems are presented in 
Table 4. As can be seen, findings are generally in accordance with the hypotheses we proposed for demonstrating convergent and discriminant validity of scores from the All.

TABLE 4: Associations between All scores and emotion regulation strategies, alexithymia scores, psychological distress, and overall interpersonal problems.

\begin{tabular}{|c|c|c|c|c|c|c|c|c|c|c|c|}
\hline$\overline{\text { All variable }}$ & ERQ-R & ERQ-E & TAS-G & TAS-DIF & TAS-DDF & TAS-EOT & OQ-TD & $O Q-S D$ & OQ-IR & OQ-SR & IIIP-G \\
\hline$\overline{\text { Global Al }}$ & $.27^{* *}$ & $-.62^{* *}$ & $-67 *$ & $-.65^{* \star}$ & $-.68^{\star \star \star}$ & $-23^{* *}$ & $-.68^{* \star}$ & $-.66^{\text {t**}}$ & $-.67^{\star \star}$ & $-.47^{\star *}$ & $-.70^{* *}$ \\
\hline Experience & $.29^{* *}$ & $-.52^{\star *}$ & $-.64^{* *}$ & $-.66^{* *}$ & $-.61^{\star \star}$ & $-.19^{*}$ & $-.72^{\star \star}$ & $-.69^{* *}$ & $-.68^{\star \star}$ & $-.52^{\star \star}$ & $-.68^{* \star}$ \\
\hline Expression & $.17^{*}$ & $-.70^{\star \star}$ & $-.60^{* *}$ & $-.48^{* *}$ & $-.68^{\star \star}$ & $-.27^{\star *}$ & $-.46^{\star \star}$ & $-.44^{\star *}$ & $-.51^{* *}$ & $-.27^{\star \star}$ & $-.59^{\star \star}$ \\
\hline \multicolumn{12}{|c|}{ Specific affects } \\
\hline Interest & $.22^{* *}$ & $-.58^{\star *}$ & $-.48^{* *}$ & $-.36^{* *}$ & $-.54^{\star \star}$ & $-.26^{* *}$ & $-.41^{\star \star}$ & $-.39^{\star \star}$ & $-.40^{\star *}$ & $-.26^{\star *}$ & $-.50^{\star *}$ \\
\hline Joy & $.27^{* *}$ & $-.60^{\star *}$ & $-.52^{\star *}$ & $-.52^{* *}$ & $-.55^{\star \star}$ & -.14 & $-.66^{\star \star}$ & $-.64^{* *}$ & $-.64^{\star *}$ & $-.42^{\star *}$ & $-.60^{\star *}$ \\
\hline Tenderness & .13 & $-.57^{\star \star}$ & $-.52^{* *}$ & $-.39^{* *}$ & $-.55^{\star \star}$ & $-.30^{* *}$ & $-.45^{\star \star}$ & $-.41^{\star \star}$ & $-.49^{\star * *}$ & $-.30^{* *}$ & $-.52^{\star *}$ \\
\hline Fear & $.25^{\star *}$ & $-.44^{\star *}$ & $-.56^{\star *}$ & $-.63^{\star *}$ & $-.56^{\star \star}$ & -.08 & $-.66^{\star \star}$ & $-.66^{* *}$ & $-.58^{\star *}$ & $-.49^{* *}$ & $-.57^{\star *}$ \\
\hline Anger & .11 & $-.30^{* *}$ & $-.45^{* *}$ & $-.50^{\star *}$ & $-.42^{\star \star}$ & -.11 & $-.42^{* *}$ & $-.55^{\star \star}$ & $-.42^{* *}$ & $-.26^{* *}$ & $-.47^{\star *}$ \\
\hline Shame & $.25^{* *}$ & $-.39^{\star *}$ & $-.44^{* *}$ & $-.42^{* *}$ & $-.50^{\star \star}$ & -.12 & $-.55^{\star \star}$ & $-.52^{\star \star}$ & $-.54^{* *}$ & $-.40^{\star *}$ & $-.51^{* *}$ \\
\hline Sadness & .15 & $-.61^{\star *}$ & $-.61^{* *}$ & $-.55^{\star *}$ & $-.66^{\star \star}$ & $-.21^{\star *}$ & $-.54^{\star \star}$ & $-.51^{\star \star}$ & $-.55^{\star \star}$ & $-.40^{\star \star}$ & $-.50^{\star \star}$ \\
\hline Jealousy & .06 & $-.20^{*}$ & $-.28^{\star *}$ & $-.31^{* *}$ & $-.23^{* *}$ & -.09 & $-.23^{* *}$ & $-.21^{* *}$ & $-.25^{* \star *}$ & $-.19^{*}$ & $-.34^{* *}$ \\
\hline Guilt & $.28^{* *}$ & $-.28^{\star *}$ & $-.44^{* *}$ & $-.45^{* *}$ & $-.40^{\star \star}$ & $-.16^{*}$ & $-.47^{* *}$ & $-.45^{\star \star}$ & $-.46^{\star *}$ & $-.32^{\star *}$ & $-.46^{* *}$ \\
\hline
\end{tabular}

Note: Global Al = global affect integration; ERQR = reappraisal; ERQ-E= expression suppression; TAS-G = global alexithymia; TAS-DIF = difficulty identifying feelings; TAS-DDF = difficulty describing feelings; TAS-EOT = externally-oriented thinking; OQ-TD = total psychological distress;

$\mathrm{OQ}-\mathrm{SD}=$ symptom distress; $\mathrm{OQ}-\mathrm{IR}=$ interpersonal distress; $\mathrm{OQ}-\mathrm{SR}=$ social dysfunction; IIP-G = global interpersonal problems ${ }^{*} p<.05 .{ }^{* \star} p<.01$

Regarding emotion regulation, we expected that All scores in general would be less strongly correlated with the emotion-regulating process of reappraisal than with the process of expression suppression. We expected moderate positive associations with reappraisal and strong negative associations with expression suppression. Finally, we expected capacity for affect experience to be more strongly related to reappraisal than capacity for affect expression, and we anticipated the opposite to be true for expression suppression. This was the pattern we found. In all cases, tests for the significance of differences in correlation magnitude were conducted. Global affect integration was more strongly correlated with expression suppression $(r=-.62)$ than with reappraisal $(r=.27)$ (Steiger's $z=3.82, p<.01)$. When comparing capacity for affect experience and capacity for affect expression and their associations with the emotion regulation strategies of reappraisal and expression suppression respectively, we found that capacity for affect experience was more strongly correlated with reappraisal $(r=.29)$ than was capacity for affect expression $(r=.17)(z=1.99, p<.05)$, while capacity for affect expression was more strongly correlated with expression suppression $(r=.70)$ than was capacity for affect experience $(r=.52)(z=-9.27, p<.01)$.

In general, we expected strong negative associations between All scores and alexithymia. On the subscale level, we expected a differentiated pattern of correlations, with weaker associations between All scores and externally oriented thinking (EOT) than with the other alexithymia scales. For difficulty identifying feelings (DIF), we expected stronger associations with capacity for affect experience than with capacity for affect expression. Conversely, we expected difficulty describing feelings (DDF) to 
be more strongly related to capacity for affect expression. Again the findings predominantly supported our hypotheses. EOT was less strongly associated with global affect integration $(r=.23)$ than DIF $(r=.65)(z=5.57, p<.01)$ and DDF $(r=.68)(z=5.01, p<.01)$. DIF was more strongly related to capacity for affect experience $(r=.66)$ than to capacity for affect expression $(r=.48)(z=-3.76, p<.01)$. Finally, DDF was more strongly related to capacity for expression $(r=.68)$ than to capacity for experience $(r=.61)$ in terms of absolute correlation magnitude. However, this difference did not reach statistical significance $(z=1.63, p>.05)$.

We expected strong negative associations between All scores on all levels and psychological distress as measured by the OQ-45.2. On the subscale level, we expected capacity for affect experience to be more strongly related to the OQ-45.2 scores than capacity for affect expression. Here too our hypotheses were supported. We found predominantly strong negative associations with all OQ scales. Also, as we expected, capacity for affect experience was more strongly related to total psychological distress $(z=5.65, p<.01)$, symptom distress $(z=5.24, p<.01)$, interpersonal distress $(z=3.61, p<.01)$, and social dysfunction $(z=4.52, p<.01)$ than was capacity for affect expression. (See Table 4 for respective $r$ values.)

Finally, for overall levels of interpersonal problems as measured by the IIP-64, we expected and obtained strong negative associations with All scores on all levels.

Correlations between the integration of specific affects and these external criteria variables were generally in line with those found for overall affect integration, with one exception: integration of jealousy was generally only weakly or moderately related to the external criteria. The other specific affect scores were moderately or strongly related to interpersonal problems, psychological distress, alexithymia, and the emotion regulation strategy of expression suppression. Relationships between specific affect scores and the emotion regulation strategy of reappraisal and externally-oriented thinking, as measured by the TAS-20, were, as is to be expected, modest or nonsignificant.

\section{Associations with external factors: patterns of associations between integration of discrete affects and specific interpersonal problems}

As a further test of the convergent and discriminant validity of All scores, we postulated distinct sinusoidal patterns of associations between the integration of discrete affects and specific types of interpersonal problems peaking in separate and theoretically expected octants of the IIP-64. The expected and obtained patterns of correlations are presented in Figure 3. The upper left panel recapitulates the predicted patterns. The upper right panel depicts obtained correlation patterns for the integration of jealousy, tenderness, and anger. The lower left panel depicts obtained correlation patterns for integration of shame, fear, interest, and joy. Finally, the lower right panel depicts obtained correlation patterns for the integration of sadness and guilt (for which no specific predictions were made). 


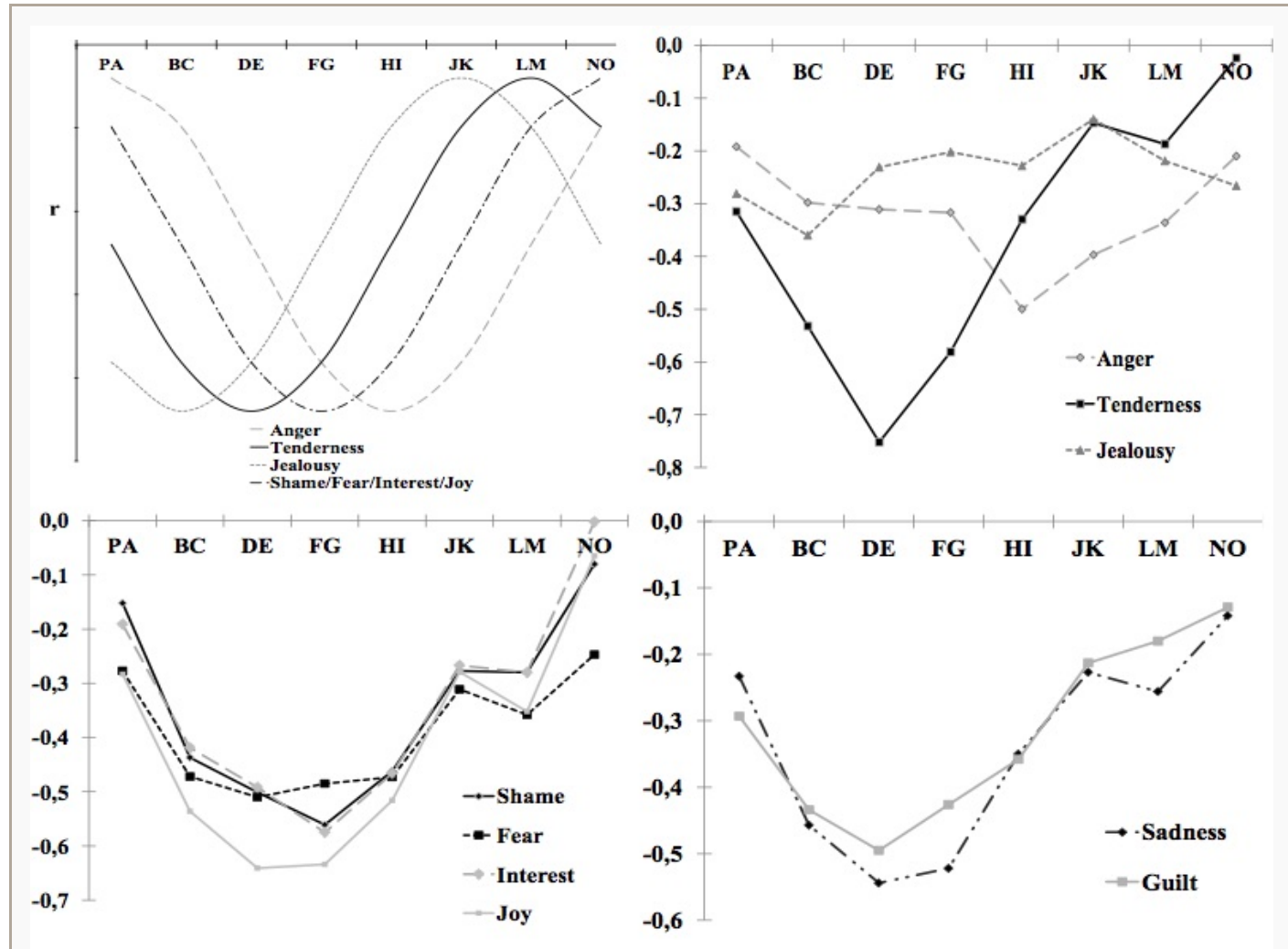

FIGURE 3: Predicted and obtained patterns of correlations between discrete affect scores from the All and IIP-64 subscales: $\mathrm{PA}$ = Domineering; $\mathrm{BC}$ = Vindictive; $\mathrm{DE}$ = Cold; FG = Socially Inhibited; $\mathrm{HI}$ = Non-Assertive; JK = Overly Accommodating; and LM = Self-Sacrificing.

As can be seen, results were generally consistent with our predictions. Integration of anger, tenderness, and jealousy all had sinusoidal or near-sinusoidal patterns of correlations, with the various interpersonal problem types having their peaks and low points in separate and expected octants. Anger peaked in the non-assertive octant (i.e., problems with anger integration were most strongly associated with nonassertiveness), tenderness peaked in the cold octant (i.e., problems with tenderness were most strongly associated with coldness and detachment), and jealousy peaked in the vindictive octant (i.e., problems with jealousy were most strongly associated with interpersonal vindictiveness). Also in line with our predictions, integration of shame and interest both had sinusoidal correlation patterns peaking in the expected sociallyinhibited octant and low points in the oppositely located intrusive octant. Integration of joy and fear showed near sinusoidal patterns of correlations, having low points in the expected intrusive octant. Both, however, had their peak correlations slightly rotated clockwise in interpersonal space, so that they peaked in the neighboring cold octant rather than the expected socially-inhibited octant. In both cases, however, the differences in correlation magnitude with the cold and socially-inhibited octants respectively were close to zero (.01 for joy and .02 for fear). For both of these affects, correlations were somewhat stronger with the overly nurturant octant than expected.

Finally, for the two affects for which no specific predictions were made (i.e., sadness and guilt), near sinusoidal patterns of associations were in fact detected. Both peaked 
in the cold octant and had their lowest association with the intrusive octant. For all nine affects, there was a statistically significant difference in correlation magnitude for the peak and the low point in the correlation pattern $(p<.05)$.

\section{Discussion}

The present study tested a new self-report instrument for assessing capacity for affect integration: the Affect Integration Inventory (AII). Reliability and validity of the All was examined in data from 157 non-clinical respondents through estimates of internal consistency reliability, examination of internal structure by principal component analyses, and tests of convergent and discriminant relationships to a number of external criteria measures. We also tested the usefulness of systematic differentiation of a substantial number of discrete affects by examining distinct patterns of theoretically-expectable relationships between the capacity for integration of separate affects and specific types of interpersonal problems. Table 5 summarizes our hypotheses and indicates whether the obtained results supported them.

TABLE 5: Summary of hypotheses and obtained results.

\begin{tabular}{|c|c|}
\hline Hypothesis & Obtained result \\
\hline $\begin{array}{l}\text { 1. Discrete affects will emerge as factors in the } \\
\text { factor analysis of experience and expression } \\
\text { scores across affects. }\end{array}$ & Supported \\
\hline $\begin{array}{l}\text { 2. Affect scores will be organized according to } \\
\text { three main dimensions commonly thought to } \\
\text { underlie affective space. }\end{array}$ & Supported \\
\hline $\begin{array}{l}\text { 3. There will be robust and differentiated } \\
\text { associations between All scores and the emotion } \\
\text { regulation strategies of reappraisal and expression } \\
\text { suppression. }\end{array}$ & Supported \\
\hline $\begin{array}{l}\text { 4. Global affect integration will be more strongly } \\
\text { related to expression suppression than to } \\
\text { reappraisal. }\end{array}$ & Supported \\
\hline $\begin{array}{l}\text { 5. Capacity for affect experience will be more } \\
\text { strangly related to reappraisal than capacity for } \\
\text { affect expression. }\end{array}$ & Supported \\
\hline $\begin{array}{l}\text { 6. Capacity for affect expression will be more } \\
\text { strongly related to expression suppression than to } \\
\text { reappraisal. }\end{array}$ & Supported \\
\hline $\begin{array}{l}\text { 7. There will be strong associations between All } \\
\text { scores on all levels and alexithymia. }\end{array}$ & Supported \\
\hline $\begin{array}{l}\text { 8. All scores will be less strongly associated with } \\
\text { the alexithymia subscale externally-oriented } \\
\text { thinking than with the difficulty identifying and } \\
\text { difficulty describing feelings subscales. }\end{array}$ & Supported \\
\hline $\begin{array}{l}\text { 9. Capacity for affect experience will be more } \\
\text { strongly related to difficulty identifying feelings than } \\
\text { to difficulty describing feelings. }\end{array}$ & Supported \\
\hline $\begin{array}{l}\text { 10. Capacity for affect expression will be more } \\
\text { strongly related to difficulty describing feelings than } \\
\text { to difficultv identifvina feelinas. }\end{array}$ & Not supported \\
\hline
\end{tabular}


16. There will be a sinusoidal pattern of associations between the integration of anger and the interpersonal problems peaking in the nonthe interpersonal
assertive octant.

17. There will be a sinusoidal pattern of associations between the integration of jealousy and the interpersonal problems peaking in the vindictive octant.

18. There will be a sinusoidal pattern of associations between the integration of interest and shame respectively and the interpersonal problems peaking in the socially avoidant octant.

19. There will be a sinusoidal pattern of associations between the integration of joy and fear respectively and the interpersonal problems peaking in the socially avoidant octant.

\section{Reliability}

Internal consistency reliability was generally high for scores derived from the All, indicating that the selection of items constituting the subscales within the study domain is reasonably sound. There was, however, one exception: integration of shame had a Cronbach's alpha of .57. This is somewhat lower than the .60 ordinarily deemed adequate. Upon examination of inter-item relations within the integration of shame scale, we found that two items contributed substantially to reduced reliability. The removal of any one of these two yielded an alpha for the remaining set greater than .60. Both items concerned the capacity to use shame as a source of useful information about one's own behavior and appeared to have been responded to in a somewhat unexpected way. Essentially, respondents reporting low scores on other shame items more often than expected delivered relatively high scores on these two items.

When we computed Cronbach's alpha for the remaining 10 items it was .70 . Cronbach's alpha for the two items contributing to the low reliability, when entered separately, was .75. Thus, it appears that the two items unexpectedly constituted a separate facet in the scale. It may therefore be reasonable to revise these items in future studies of the All. An implication for the present study is that our findings on the integration of shame must be interpreted with some caution. Fortunately, however, 
since there appear to be two facets within the shame scale, its reliability is probably underestimated by the alpha value. A more realistic estimate would be constituted by computing the mean alpha across the two facets, as would be done when computing the overall reliability of a multidimensional composite. Thus, we do believe that reasonably reliable and meaningful conclusions can be drawn from our analyses of the integration of shame despite its somewhat weak alpha value. To test whether excluding the two low-reliability items would impact results, we computed an integration of shame score based on the remaining 10 items and examined its associations with the various external criteria variables. This had little impact on the results beyond making the pattern of associations with interpersonal problem domains even more distinctly sinusoidal and yielding somewhat stronger associations overall.

\section{Internal structure}

The factor analysis of experience and expression scores across affects indicated that All ratings reflect their conceptual basis quite well. Ratings generally appear to be represented by expected factors, each reflecting a discrete affect category. The obtained factor structure is consistent with the central conceptual assumption of the affect integration construct, namely that different affects have different motivational and signal properties and therefore should be differentiated in assessment. This finding is in line with the discrete affect approaches, such as those advocated by Tomkins (2008a, 2008b), Izard (2007; 2009), and Panksepp (2007). It also carries with it the general implication that the measurement of affect-related capacities needs to take a more differentiated perspective than what is at this time typical.

Only two variables had loadings that deviated from the expected structure. Those deviations indicate that the Integration of Fear and Interest factors are less distinctly represented in the data than the other factors are. For both of them, the respective expression variables received stronger loadings from one other factor than from the theoretically-expected one. In both cases, the cross-loading came from a conceptually similar or related affect factor (expression of interest from joy and expression of fear from sadness) and thus was not entirely unexpected. Future studies in larger samples will be needed to determine whether this is a finding that will reproduce itself across studies and populations or if it is a random occurrence of the present sample. Overall, we do believe that the obtained factor structure is remarkably good, given the complexity of the data and the sheer number of affects to be differentiated in the analyses.

Turning to the principal component analysis of discrete affect scores, the match between affects in the All and the various related emotion categories from Fontaine et al. (2007) was, in our opinion, quite notable. Since All data are conceptually very different from the data obtained by Fontaine et al., we believe important further support is constituted not only for the soundness of the All in terms of its internal structure but also as a direct source of evidence for the conclusions drawn by Fontaine and colleagues. The fact that the dimensions derived from All data correspond well to 
those of Fontaine et al. indicates that this structure goes beyond the mere description of emotions and affective states on the semantic or lingual level (which was what Fontaine et al. ultimately tested with their study) in that it also applies to the domain of how people experience and deal with different emotions.

Looking at specific deviations from the expected structure, there appears to be only one substantial difference in terms of localization of All affect scores: the localization of guilt and shame on the activation/arousal dimension. While being highly similar in terms of arousal in Fontaine et al.'s study, these two are separated as high and low on arousal respectively in our data. From both a theoretical and empirical point of view, we believe that our finding makes good sense: shame is traditionally conceptualized as a response associated with the shutting down of ongoing activity (Tomkins, 2008a, 2008b) and has been found to be associated with a reduction in arousal as indexed by lowered heart rate (Ekman, Levenson, \& Friesen, 1983). Guilt on the other hand has been shown to include high sympathetic autonomous nervous system activity as manifested through elevated heart rates and skin conductance (Ekman et al., 1983). Thus, our finding of guilt and shame as respectively high and low on activation/arousal appears to map better to the existing literature than that of Fontaine et al.

In sum, it appears that the internal structure of affect scores from the All is sound in terms of its higher-order factor organization. However, our findings are not sufficient for demonstrating sound structure on the single item level. Future studies therefore should include sufficiently large samples for first-order factor structure (i.e., on the single item level) of the All to be examined.

\section{Associations with emotion regulation, alexithymia, and psychological distress}

Overall, the predicted relationships postulated to demonstrate convergent and discriminant validity of All scores were supported by our data. It appears that affect integration, as assessed by the All, is closely linked to other concepts measuring affective functioning such as alexithymia and emotion regulation. It also appears that the validity of distinguishing between capacity for experience and capacity for expression is supported by theoretically consistent patterns of convergent and discriminant associations with the experiential and expressive subdomains of these concepts. Also, as was expected, it appears that affect integration is more closely linked to those subdomains of alexithymia and emotion regulation that specifically include indicators of capacity for differentiating, accepting, describing, and clearly expressing emotions than it is to the two subdomains of 1 ) externally-oriented thinking and 2) reduction in the impact of emotions by reappraising affect-eliciting situations primarily in a positive manner. We believe that these findings give credence not only to the validity of the All but also to the conceptualizations of the ERQ and the TAS-20. As far as we know, no previous study has demonstrated with such clarity the convergent and discriminant validity of subdomains for these measures.

Looking at separate affects from the All and their relationships to the emotion regulation strategy of reappraisal and the alexithymia subdomain of externally-oriented 
thinking, we see that there are some discrete affect scores that are related to these variables, while others are not. This tendency may indicate that these facets of emotion regulation and alexithymia are, in fact, specifically related to the capacity for experiencing and expressing only some affects or types of affect. This would be an interesting area for future research that could shed light on the potentially complex interrelationships between capacity for effective handling of discrete affects and more general strategies of emotion regulation or styles of psychological functioning (e.g., reappraisal and "mechanical" or externally-oriented thinking).

As we expected, there were strong associations between affect integration on all levels and psychological distress. Our results indicate that capacity for dealing effectively with emotion can explain a substantial proportion of the variation in psychological symptoms, interpersonal distress, and social role dysfunction. Furthermore, in line with theoretically derived expectations, our data confirm that reporting high levels of psychological distress probably depends more on inadequate capacity for experiencing affects than on inadequate capacity for expressing them. Results are consistent with those found in previous studies examining the relationship between symptomatic distress and affect integration through the use of the ACl (e.g., Solbakken et al., 2011b). However, the magnitudes of association are somewhat higher, possibly due to the use of self-report in both measurement domains in the current study.

\section{Associations with general and specific interpersonal problems}

Our data support the notion that capacity for experiencing and expressing affects is of central importance for relational functioning. All scores on all levels were strongly associated with the overall level of interpersonal problems reported by the respondents. As much as $49 \%$ of the variation in interpersonal problems at the overall level was explained by global affect integration. Again, results are in line with previous research on affect integration and interpersonal functioning that used the $\mathrm{ACl}$ but with somewhat stronger associations than previously reported.

Looking at the relationships between the integration of specific affects and the various types of interpersonal problems operationalized by the IIP-64, there is remarkable overlap between hypothesized and obtained correlation patterns. Integration of anger, tenderness, jealousy, interest, and shame all had the expected patterns of associations. Integration of joy and fear had correlation patterns that were slightly rotated in the interpersonal space compared to our expectations. The deviation from our hypotheses was, however, very small in terms of absolute numbers.

For the integration of tenderness and anger, the current findings replicate previous studies using the ACI (Normann-Eide et al., 2013; Solbakken et al., 2011b). For the other discrete affects, the demonstration of such differentiated patterns of theoretically predictable associations with different types of interpersonal problems is, as far as we are aware, a first in the literature. Interestingly, distinct correlation patterns also were found for the integration of sadness and guilt. Both had near-sinusoidal patterns of 
associations peaking in the cold octant (i.e., problems with the integration of these two affects were most strongly associated with interpersonal coldness and detachment). We felt we did not have clear grounds for making hypotheses about how these affects would relate to various interpersonal problems. However, with the guidance of 20/20 hindsight, we do believe that this finding makes good conceptual sense. Sadness is an affect associated with dealing with interpersonal loss and communicating a need for connection and comfort, while guilt usually is associated with a need for reparation for the damage one has caused to others and one's bond to them. Thus, it makes sense that problems with these two affects are especially pertinent to interpersonal difficulties associated with bonding and disrupted attachment to others.

Overall, we believe that our findings offer strong support for the convergent and discriminant validity of discrete affect scores from the All. More specifically, convergent validity was demonstrated by correlation patterns commonly peaking on predicted and separate octant scales of the IIP-64. Discriminant validity was shown by low associations with octants located oppositely to the expected peaks and by the demonstration of sinusoidal or near-sinusoidal rank order of correlations.

In addition to offering highly promising data on the construct validity of scores from the All, these findings offer further support for the notion of a differentiated affect system and for the utility of differentiation between affects in assessment (Solbakken et al., 2011b). We believe that the differentiated correlation patterns between the integration of various affects and interpersonal functioning indicate that the motivational and signal properties of these affects are distinctly associated with different interpersonal behaviors. We also believe that problems with these affects systematically give rise to different interpersonal problems.

\section{The case of jealousy}

Results obtained for the integration of jealousy merit some specific discussion. Capacity for experiencing and expressing jealousy was significantly related to the expected external criteria variables. However, the magnitudes of those correlations were generally weaker than for the other discrete affects. Correlations could largely be classified as small, with some of medium size. Interestingly, this mirrors previous findings on jealousy using the ACI. Solbakken et al. (2011b) found only small correlations between the integration of envy/jealousy and psychiatric symptoms, personality dysfunction, general psychological functioning, and overall levels of interpersonal problems.

A conceivable explanation pointed to by Solbakken and associates (2011b) is a possible tendency to deny the impact of jealousy more than what is common for other unpleasant affects, especially among better functioning individuals. The present findings using self-report seem to support their conjecture that jealousy may be a more socially unacceptable and thus more conflicted emotion even among better functioning individuals than the other unpleasant emotions. 


\section{Limitations and recommendations for future research}

The present study represents a relatively comprehensive first validation of the All. Still, there are some limitations that should be noted, as well as some recommendations for future studies in the field.

One important limitation is the fact that we did not include the $\mathrm{ACl}$ in the study. Thus, even though we included external criteria measures conceptually similar to affect integration as operationalized in the $\mathrm{ACl}$ or All, we cannot test the extent to which selfreported and observer based ratings of affect integration overlap. Ideally, these two measurement procedures will produce highly correlated scores. This, however, we cannot demonstrate with our study. It is therefore important that future studies collect concurrent data with both the All and the ACI.

On a similar note, the present study lacks data on the temporal stability of scores from the All. Accordingly, it would be helpful if future studies collected data in which the All is administered repeatedly to the same respondents, thereby making it possible to examine test-retest reliability.

Another limitation is that the study demonstrates the psychometric properties of the All in only a sample of respondents with relatively low levels of psychological distress. It is not necessarily so that these results generalize to other populations. Since affect integration is essentially a clinically-oriented construct, it is very important that we also get data on how the All works in clinical samples. Future studies should therefore examine the psychometric properties of the All in various clinical populations. Such studies should also examine the usefulness of the All as an outcome measure in psychotherapy research and its potential as an instrument in the planning of psychotherapeutic interventions and treatment.

The first-order (or single-item) factor structure of scores from the All was not explored in the present study. Doing so will be important in future studies. Interestingly, Solbakken et al. (2011b) have shown that the first-order factor structure of scores from the $\mathrm{ACl}$ is organized systematically according to discrete affects. If the same is true for the All, it would constitute further evidence for the differentiated nature of the affect system. To investigate this issue, future studies need to include relatively large samples, perhaps as many as 600 respondents if the common convention of a 5-to-1 respondent-to-variable ratio is to be respected.

Finally, all domains assessed in the present study were measured through self-report questionnaires. This approach will usually inflate associations between various variables due to what is called common method variance (i.e., the covariance between variables that exists purely because the same assessment methods or sources of information have been employed). Thus, associations may be somewhat overestimated. However, we do believe that the systematic patterns of theoretically expected convergent and discriminant validity coefficients obtained indicate that common method variance is not a severe threat to the validity of our results. Still, future 
studies would ideally include assessments using different methods of data collection to reduce any such bias.

\section{Conclusion}

Overall, the present study indicates that scores from the All are adequate in terms of reliability. Furthermore, their higher-order factor structure (in terms of the integration of discrete affects) appears to conform well to the theoretical model upon which the construct rests. Associations with external criteria indicate robust and theoretically predictable relationships, both on global and specific levels. Systematic and differentiated patterns of convergent and discriminant relationships with external criteria were demonstrated for global affect integration, capacities for experience, and expression of affect and for the integration of discrete affects. There is thus preliminary, but seemingly solid, support for the construct validity of the affect integration construct as it is operationalized in the All.

Our results are generally consistent with earlier findings but also extend upon previous knowledge by demonstrating novel aspects of construct validity for the concept of affect integration. Results of this study bolster earlier conclusions from research on affect integration, indicating that research in the realm of the clinical and functional understanding of affect should include a more thorough differentiation of affect states than is ordinarily the case.

Perhaps the most exciting conclusion to be drawn from the present study is that reliable and valid assessment of affect integration appears to be possible through a reasonably time-efficient self-report format. Previously, the potential proliferation of the affect integration construct had been reduced due to the demands of training necessary for mastering the $\mathrm{ACl}$ and the amount of time required for conducting and rating interviews. The present article constitutes the first empirical validation of the All, a measure that appears to make reliable and valid assessment of affect integration available to those who do not have time for extensive clinical interviewing and access to adequate interview training. Hopefully the present paper will thereby lay the grounds for many new studies and make the empirical examination of affect integration accessible to a large number of new, interested researchers across the world.

\section{References}

Bagby, R. M., Parker, J. D., \& Taylor, G. J. (1994). The twenty-item Toronto Alexithymia Scale-I. Item selection and cross-validation of the factor structure. Journal of Psychosomatic Research, 38(1), 23-32. doi:10.1016/0022-3999(94)90005- 
Choi-Kain, L. W., \& Gunderson, J. G. (2008). Mentalization: Ontogeny, assessment, and application to the treatment of borderline personality disorder. American Journal of Psychiatry, 165, 1127-1135. doi:10.1176/appi.ajp.2008.07081360

Damasio, A. (1999). The Feeling of What Happens: Body and Emotion in the Making of Consciousness. Fort Worth: Harcourt College Publishers.

Damasio, A. R. (2004). Looking for Spinoza: Joy, Sorrow, and the Feeling Brain. New York: Random House.

Ekman, P., Levenson, R. W., \& Friesen, W. V. (1983). Autonomic nervous system activity distinguishes among emotions. Science, 221(4616), 1208-1210.

doi:10.1126/science.6612338

Falkenström, F., Solbakken, O. A., Möller, C., Lech, B., Sandell, R., \& Holmqvist, R. (2014). Reflective functioning, affect consciousness, and mindfulness: Are these different functions? Psychoanalytic Psychology, 31(1), 26. doi:10.1037/a0034049

Fonagy, P., Gergely, G., Jurist, E. L., \& Target, M. (2002). Affect Regulation, Mentalization, and the Development of the Self. New York: Other Press.

Fontaine, J. R., Scherer, K. R., Roesch, E. B., \& Ellsworth, P. C. (2007). The world of emotions is not two-dimensional. Psychological Science, 18(12), 1050-1057. doi:10.1111/j.1467-9280.2007.02024.x

Gross, J. J. (2007). Emotion regulation: Conceptual foundations. In J. J. Gross (Ed.), Handbook of Emotion Regulation, (pp. 3-24). New York: Guilford.

Gross, J. J., \& John, O. P. (2003). Individual differences in two emotion regulation processes: Implications for affect, relationships, and well-being. Journal of Personality and Social Psychology, 85(2), 348. doi:10.1037/0022-3514.85.2.348

Gude, T., Monsen, J. T., \& Hoffart, A. (2001). Schemas, affect consciousness, and cluster c personality pathology: A prospective one-year follow-up study of patients in a schema-focused short-term treatment program. Psychotherapy Research, 11, 8598. doi:10.1080/713663854

Holmqvist, R. (2008). Psychopathy and affect consciousness in young criminal offenders. Journal of Interpersonal Violence, 23, 209-

224. doi:10.1177/0886260507309341

Horowitz, L.M., Alden, L.E., Wiggins, J.S., \& Pincus, A.L. (2000). Inventory of Interpersonal Problems Manual. Odessa: The Psychological Corporation.

Izard, C. E. (2007). Basic emotions, natural kinds, emotion schemas, and a new paradigm. Perspectives on Psychological Science, 2, 260-280. doi:10.1111/j.1745- 
Izard, C. E. (2009). Emotion Theory and Research: Highlights, unanswered questions, and emerging issues. Annual Review of Psychology, 60, 125. doi:10.1146/annurev.psych.60.110707.163539

Izard, C. E., \& Ackerman, B. P. (2000). Motivational, organizational, and regulatory functions of discrete emotions. In M. Lewis \& J. M. Haviland Jones (Eds.), Handbook of Emotions (2 ${ }^{\text {nd }}$ ed.), (pp. 253-264). New York: Guilford Press.

Izard, C. E., Stark, K., Trentacosta, C., \& Schultz, D. (2008). Beyond emotion regulation: Emotion utilization and adaptive functioning. Child Development Perspectives, 2, 156-163. doi:10.1111/j.1750-8606.2008.00058.x

Johansen, M. S., Normann-Eide, E., Normann-Eide, T., \& Wilberg, T. (2013). Emotional dysfunction in avoidant compared to borderline personality disorder: A study of affect consciousness. Scandinavian Journal of Psychology, 54(6), 515521. doi:10.1111/sjop.12076

Jurist, E. L. (2005). Mentalized Affectivity. Psychoanalytic Psychology, 22, 426444. doi:10.1037/0736-9735.22.3.426

Krystal, H. (1974). The genetic development of affects and affect regression. The Annual of Psychoanalysis, 2, 98-126.

Lane, R.D., Quinlan, D.M., Schwartz, G.E., Walker, P.A., \& Zeitlin, S.B. (1990). The levels of emotional awareness scale: A cognitive-developmental measure of emotion. Journal of Personality Assessment, 55, 124-134.

doi:10.1207/s15327752jpa5501\&2_12

Lambert M., Morton J., Hatfield D., Harmon C., Hamilton S., et al. (2004).

Administration and Scoring Manual for the Outcome Questionnaire-45. Salt Lake City, UT: OQ Measures.

Lech, B., Andersson, G., \& Holmqvist, R. (2008). Consciousness of own and others' affects: A study of the validity of a revised version of the Affect Consciousness Interview. Scandinavian Journal of Psychology, 49, 512-521. doi:10.1111/j.14679450.2008.00666.x

LeDoux, J. E. (1996). The Emotional Brain: The Mysterious Underpinnings of Emotional Life. New York: Simon \& Schuster.

Lesser, I. M. (1981). A review of the alexithymia concept. Psychosomatic Medicine, 43, 531-540. doi:10.1097/00006842-198112000-00009

McCullough Vaillant, L. (1997). Changing Character. New York: Basic Books.

Monsen, J. T., Eilertsen, D. E., Melgard, T., \& Ødegard, P. (1996). Affects and affect consciousness: Initial experiences with the assessment of affect integration. Journal of 
Psychotherapy Practice and Research, 5, 238-249.

Monsen, J. T., Hagtvet, K. A., Havik, O. E., \& Eilertsen, D. E. (2006). Circumplex structure and personality disorder correlates of the Interpersonal Problems Model (IIPC): Construct validity and clinical implications. Psychological Assessment, 18, 165173. doi:10.1037/1040-3590.18.2.165

Monsen, J. T., \& Monsen, K. (1999). Affects and affect consciousness:

A psychotherapy model integrating Silvan Tomkins' affect and script theory within the framework of self-psychology. In A. Goldberg (Ed.), Pluralism in Self-Psychology: Progress in Self-Psychology, Vol. 15. Hillsdale, NJ: Analytic Press.

Monsen, J. T., Monsen, K., Solbakken, O. A., \& Hansen, R. S. (2008). The Affect Consciousness Interview (ACl) and the Affect Consciousness Scales (ACS): Instructions for the interview and rating. Available from the Department of Psychology, University of Oslo.

Monsen, J. T., Melgård, T., \& Ødegård, P. (1986). Affektbevissthetsintervjuet, instruksjoner for intervju og skåring. Unpublished manual, University of Oslo.

Monsen, J. T., Ødegård, P., \& Melgård, T. (1989). Major psychological disorders and changes after intensive psychotherapy: Findings from the Tøyen Project, Oslo.

Psychoanalysis and Psychotherapy, 7, 171-180.

Normann-Eide, E., Johansen, M. S., Normann-Eide, T., Egeland, J., \& Wilberg, T. (2013). Is low affect consciousness related to the severity of psychopathology? A cross-sectional study of patients with avoidant and borderline personality disorder. Comprehensive Psychiatry, 54(2), 149-157. doi:10.1016/j.comppsych.2012.07.003

Panksepp, J. (1998). Affective Neuroscience. The Foundations of Human and Animal Emotions. New York: Oxford University Press.

Salovey, P., \& Mayer, J. D. (1990). Emotional intelligence. Imagination, Cognition, and Personality, 9(3), 185-211. doi:10.2190/DUGG-P24E-52WK-6CDG

Solbakken, O. A. (2011). Affect integration, psychopathology, and psychotherapy: Conceptual issues, construct validity, and the prediction of change. University of Oslo, Norway: Doctoral dissertation.

Solbakken, O. A., Hansen, R. S., \& Monsen, J. T. (2011a). Affect integration and reflective function: Clarification of central conceptual issues. Psychotherapy Research, 21, 482-496. doi:10.1080/10503307.2011.583696

Solbakken, O.A., Hansen, R.S., Havik, O.E., \& Monsen, J.T. (2011b). The assessment of affect integration: Validation of the affect consciousness construct. Journal of Personality Assessment, 93, 257265. doi:https://doi.org/10.1080/00223891.2011.558874. 
Solbakken, O. A., Hansen, R. S., Havik, O. E., \& Monsen, J. T. (2012). Affect integration as a predictor of change: Affect consciousness and treatment response in open-ended psychotherapy. Psychotherapy Research, 22(6), 656-672. doi:10.1080/10503307.2012.700871

Solbakken, O. A., \& Monsen, J. T. (2013). The Affect Integration Inventory (AII) a self-report instrument for assessing affect integration. Oslo, Norway: The Department of Psychology, University of Oslo.

Spaapen, D. L., Waters, F., Brummer, L., Stopa, L., \& Bucks, R. S. (2014). The Emotion Regulation Questionnaire: Validation of the ERQ-9 in two community samples. Psychological Assessment, 26 (1), 46-54. doi:10.1037/a0034474

Stolorow, R. D., Brandchaft, B., \& Atwood, G. E. (1995). Psychoanalytic Treatment: An Intersubjective Approach. Hillsdale: The Analytic Press, Inc.

Taarvig, E., Solbakken, O. A., Grova, B., \& Monsen, J. T. (2014). Affect consciousness in children with internalizing problems: Assessment of affect integration. Clinical Child Psychology and Psychiatry, 20(4), 591-610. doi:10.1177/1359104514538434

Tomkins, S. S. (1963). Affect Imagery Consciousness: Volume II: The Negative Affects. New York: Springer Publishing Company, LCC.

Tomkins, S. S. (1995). Script theory. In E. V. Demos (Ed.), Exploring Affect. The Selected Writings of Silvan Tomkins. New York: University of Cambridge Press. doi:10.1017/cbo9780511663994.021

Tomkins, S. S. (2008a). Affect Imagery Consciousness: The Complete Edition. Volumes I and II. New York: Springer Publishing Company.

Tomkins, S. S. (2008b). Affect Imagery Consciousness: The Complete Edition. Volumes III and IV. New York: Springer Publishing Company.

Waller, E., \& Scheidt, C. E. (2004). Somatoform disorders as disorders of affect regulation. A study comparing the TAS-20 with non-self-report measures of alexithymia. Journal of Psychosomatic Research, 57, 239-247. doi:10.1016/S00223999(03)00613-5

Citation

Solbakken, O. A., Rauk, M., Solem, A., Lødrup, W., \& Monsen, J. T. (2017). Tell me how you feel and I will tell you who you are: First validation of the affect integration inventory. Scandinavian Psychologist, 4, e2.

https://doi.org/10.15714/scandpsychol.4.e2

Abstract 


\section{Tell me how you feel and I will tell you who you are: First validation of the affect integration inventory}

Affect integration, or the capacity to utilize affects for personal adjustment, is an essential aspect of psychological functioning. Affect integration has been operationalized through the affect consciousness construct as degrees of awareness, tolerance, nonverbal expression, and conceptual expression of nine discrete affects. It is measured by the Affect Consciousness Interview ( $\mathrm{ACl})$. The $\mathrm{ACl}$, however, is timeconsuming and demands extensive training. It is therefore a priority to develop a selfrated measure of affect integration that is more readily accessible. This study explored the validity of the Affect Integration Inventory (AII), a self-rated operationalization of affect integration, through estimates of internal consistency and internal structure. External validity was addressed by examining relationships between All scores and emotion regulation, alexithymia, psychiatric symptoms, and interpersonal problems. We found satisfactory reliability, sound internal structure, and associations with external criteria, indicating good convergent and discriminant validity. Such findings included distinct relationships between All ratings and specific types of interpersonal problems.

Keywords: affect integration, alexithymia, assessment, emotion, emotion regulation, interpersonal problems, psychiatric symptoms.

Author affiliation: Ole André Solbakken, Mari Rauk, Anders Solem, William Lødrup, \& Jon T. Monsen1 - Department of Psychology, University of Oslo, Oslo, Norway.

Contact information: Ole André Solbakken, Department of Psychology, University of Oslo, Pb. 1094 Blindern, N-0317 Oslo, Norway.

Email: o.a.solbakken@psykologi.uio.no.

Received: August 8, 2016. Accepted: December 16, 2016. Published: January 21, 2017.

Language: English.

Competing interests: The authors report no conflict of interest. The authors alone are responsible for the contents and writing of this paper.

This is a peer-reviewed paper.

\section{Ole André Solbakken}

Ole André Solbakken is an associate professor at the Department of Psychology, University of Oslo, Norway.

\section{Mari Rauk}


Mari Rauk is a psychologist and an affiliate of the Department of Psychology, University of Oslo, Norway.

\section{Anders Solem}

Anders Solem is a psychologist and an affiliate of the Department of Psychology, University of Oslo, Norway.

\section{William Lødrup}

William Lødrup is a psychologist and an affiliate of the Department of Psychology, University of Oslo, Norway.

\section{Jon T. Monsen}

Jon Trygve Monsen is a professor at the Department of Psychology, University of Oslo, Norway. 